\title{
Spectral Analysis and Antibacterial Activity of Methanol Extract of Roots of Echinops echinatus and its Fractions
}

\author{
Muhammad Younus ${ }^{1}$, Farrakh Zia Khan ${ }^{2}$, Sabira Sultana ${ }^{1 *}$ and Hafiz Muhammad Asif ${ }^{1}$ \\ ${ }^{1}$ Department of Pharmacy, Faculty of Pharmacy and Alternative Medicine, The Islamia University of Bahawalpur, Pakistan \\ ${ }^{2}$ University College of Pharmacy, University of the Punjab, Lahore, Pakistan
}

\begin{abstract}
Objective: The root of Ecinops echiantus L. (Asteraceae) is reported to have great medicinal value. The aim of the present study was to determine the chemical profile of methanol extract of Echinops echiantus by two different spectral analyses which will be useful for its proper identification when therapeutically used. Isolated compounds and crude methanol extract were screened for antibacterial activity.

Methods: Spectral analysis was done by different analytical methods such as Infrared spectroscopy (FTIR) and Ultraviolet spectroscopy. The in vitro antibacterial activity of $E$. echinatus root extracts was studied by the hole plate diffusion method against several human pathogenic gram positive and gram negative bacteria.

Results: Five compounds were isolated from crude methanol extract using column chromatography and characterized by techniques like Infrared spectroscopy (FTIR) and Ultraviolet spectroscopy. Compounds showed different $\mathrm{Rf}$ values ranging from 67 to 9.4. All the five isolated compound and crude methanol extract showed significant antibacterial activity against all strains. However, maximum activity shown by compound Ee-4, Ee-1, Ee-3 against Staphylococcus aureus $(17.0 \mathrm{~mm}),(15.3 \mathrm{~mm}),(12.3 \mathrm{~mm})$ respectively. While Ee-5 give maximum activity against $E$. coli $(13.5 \mathrm{~mm})$.

Conclusion: The result of this study suggested that methanol extract of Echinops echiantus root and its isolated compounds exhibited marked antibacterial activity. Therefore, the results of this study may act as biochemical markers for this medicinally important plant in the pharma industry and plant systematic studies.
\end{abstract}

Keywords: Echinops echinatus; Antibacterial; Isolation; Column chromatography; Hole plate diffusion method

\section{Introduction}

The genus Echinops (Fam. Asteraceae) is thiste-like herb, consisting of 7 species in Pakistan and about 82 species in Eastern and southern Europe, Tropical and North Africa and Asia. Out of these species, E. echinatus and E. niveus are commonly found [1]. Echinops echinatus is an erect, 1-3 ft. high low growing much branched herb with white cotton stems. This xerophytic weed is widely distributed in deserted places and foothills of Potohar region; and is indigenous of Eurasia and Africa and its distribution extends from Asia through Afghanistan, Pakistan, India up to Japan. It is common in Lahore district and found in Himalayas ascending to $1500 \mathrm{~m}$, Chilas, Hunza, Baltistan and Las Bela. In Potohar region of Punjab, it is mostly distributed in the areas near Roomian and Dhakner village of Attock district, in the area between Doke Sadwal to Bhait and Tilla Gogian, Jhelum district, the areas between Kahuta and Rawalpindi, Chakwal and Attock district. The Species E. echinatus is, in fact, found throughout Potohar belt, but its distribution is not uniform in the region and is found in restricted localized areas [2]. Phytochemical investigation of the whole plant or its specific part has been done by many research workers and a number of active constituents have been isolated. The variety of these compounds belong to various classes viz. alkaloids, terpenoids, flavonoids, steroids, etc. [3,4]. Prabir identified a new acylated flavone in E. echinatus as apigenin 7-O-B-D(4"-cis-p-coumaroyl) glucoside from spectral and chemical analysis [3]. In addition to echinopsine and echinopsidine, a new alkaloid, echinozolinone was identified in E. echinatus as 3(2-hydroxylethyl$4(3 \mathrm{H})$-qunazolinone from its spectal data. This was the first report of alkaloids from this plant and the first occurrence of 4-quinazolinone alkaloid in the Compositae [4].The ethanolic extract of powdered roots yielded allophonic acid and w-methylallophonic acid [5].The plant is diuretic, aphrodisiac and a nerve tonic. The plant is regarded useful in jaundice, hysteria, dyspepsia and is also recommended in ophthalmia. It is used in hoarseness of throat and cough. The powdered root is also used to kill lice. The plant is stomachic, anti- pyretic, analgesic, increases appetite, stimulates liver, and is used in chronic fever, pains in joints and inflammation $[2,5]$.

\section{Materials and Methods}

\section{Identification and authentication of plant material}

Echinops echinatus plant was collected from different areas around Thokar Niaz Baig and Jauhar Town, Lahore, during February, March, 2008. This was authenticated by Prof. Dr. Zaheer-ud-Din Khan, Department of Botany, Government College University, Lahore. The voucher specimen (No.GC. herb. Bot. 526, dated 11-04-2008) was deposited in the Herbarium of pharmacongosy section, University College of pharmacy, University of the Punjab, Lahore.

\section{Preparation of extract}

The whole plant was washed to remove all the external dirt and unwanted material, shade dried for $72 \mathrm{~h} .1000 \mathrm{~g}$ of powdered material was taken in a beaker having $5 \mathrm{~L}$ capacity and $2 \mathrm{~L}$ of methanol was

*Corresponding author: Sabira Sultana, Department of Pharmacy, Faculty of Pharmacy and Alternative Medicine, The Islamia University of Bahawalpur, Pakistan, Tel: 03026768718; E-mail: drsabirachishti12@gmail.com

Received May 13, 2016; Accepted June 07, 2016; Published June 14, 2016

Citation: Younus M, Khan FZ, Sultana S, Asif HM (2016) Spectral Analysis and Antibacterial Activity of Methanol Extract of Roots of Echinops echinatus and its Fractions. J Microb Biochem Technol 8: 216-221. doi: 10.4172/1948-5948.1000288

Copyright: @ $\odot 2016$ Younus M, et al. This is an open-access article distributed under the terms of the Creative Commons Attribution License, which permits unrestricted use, distribution, and reproduction in any medium, provided the original author and source are credited. 
Citation: Younus M, Khan FZ, Sultana S, Asif HM (2016) Spectral Analysis and Antibacterial Activity of Methanol Extract of Roots of Echinops echinatus and its Fractions. J Microb Biochem Technol 8: 216-221. doi: 10.4172/1948-5948.1000288

added, soaked for $72 \mathrm{~h}$ with occasional shaking and stirring. After 72 $\mathrm{h}$ the soaked material of the plant extract was filtered through several layers of muslin cloth for coarse filtration. The filtrate was filtered through a whatman \# 1 filter paper. The residues were extracted thrice with the same fresh solvent and extracts combined. The filtered extract was concentrated under reduced pressure at $40^{\circ} \mathrm{C}$, and was made free from solvent, using rotary evaporator (Tokoyo Rikakikai Co; Ltd). The crude extract so obtained was weighed to calculate the yield which was $(9.4 \% \mathrm{w} / \mathrm{w})$ and extract was stored in a refrigerator $\left(-8^{\circ} \mathrm{C}\right)$, until used for analysis.

\section{Reagents and equipments}

Methanol (Merck Germany), Glacial acetic acid, Anisadehyde, Iodine, Agar (B.D.H, Poole, England), Nutrient agar, distilled water, Acetone, gum acacia, Ampicillin pure powder (Drug testing Laboratories, 1- Bird wood road, Lahore), streptomycin pure powder (Drug testing laboratory, 1-Bird wood road, Lahore), Distillation apparatus (Quick fit, England); Rotary vacuum evaporator (Tokyo Rikakikai Co; Ltd), Electric balance (Sartorius)

\section{Column Chromatography}

A glass column of $55^{\star} 4.5 \mathrm{~cm}$. was used for column chromatography. The column was packed uniformly with $300 \mathrm{~g}$ gel G320 by wet method. Chloroform was used for packing the column. $12 \mathrm{~g}$ of methanol extract of E. echinatus was adsorbed on $10 \mathrm{~g}$ of silica gel, using $10 \mathrm{ml}$ methanol. Methanol was completely evaporated and the dried silica gel adsorbed material after pulverization was put on the top of the column. The column was first run with chloroform then the polarity of the system was changed by increasing the quantity of methanol in chloroform.

\section{Thin Layer Chromatography}

20x5 cm glass plates were used for this purpose. $30 \mathrm{~g}$ silica gel G60 made into slurry by mixing with $90 \mathrm{ml}$ of distilled water and spread uniformly on plates with the help of moving spreader Dosga applicator, which was already adjusted at $0.25 \mathrm{~mm}$. The plates were dried at room temperature and activated in oven at $110^{\circ} \mathrm{C}[6,7]$. The spots on thin layers were dried in the air and developed in the chromatographic tanks using different solvent systems as shown in the tables.

\section{Ultraviolet Visible Absorption (UV)}

The methanol extract of Echinops echanitus was analyzed in UVVisible range between 200-800 $\mathrm{nm}$ using UV-Visible Spectrophotometer (UV-1800, Shimadzu).

\section{Infra-Red Spectroscopy (IR)}

The IR spectra of methanol extract of Echinops echanitus and were scanned on FT-IR Shimadzu- 8400 over the frequency range from $4000-400 \mathrm{~cm}^{-1}$.

\section{Antibacterial Activity}

All isolated compound were screened for in vitro antibacterial activity by agar diffusion hole plate method at 50, $100 \mu \mathrm{g} / \mathrm{ml}$ concentrations against the strains Staphlococcus aureus, Streptococcus pneumoniae, Bacillis subtilis, and, E. coli, Klebsiella pneumoniae, Pseudomonas aeruginosa.

The melted nutrient agar was cooled to $45^{\circ} \mathrm{C}$, mixed with culture media by gentle shaking and then poured onto a sterilized petri dish and allowed to solidify. 7 holes in the solidified medium were made with sterile borer and were numbered one to seven. First 5 holes were filled aseptically with the isolated compounds, $6^{\text {th }}$ hole was filled with crude methanol extract and $7^{\text {th }}$ hole was filled with gum acacia solution. Another set of petri-dishes was prepared in the same way for the reference antibiotic solution. The purpose of preparation of this set was to compare the antimicrobial potential of the antibiotic solution with that of the crude extract and the purified compounds. The petri-dishes were kept in incubator at $35-38^{\circ} \mathrm{C}$ for $24 \mathrm{~h}$. Zones of inhibition in each case were observed and recorded.

\section{Results and Discussion}

The methanol extract was subjected to column chromatographic analysis to isolate compound(s) using an increasing quantity of methanol in chloroform. The elution process was monitored by TLC. Ten pooled fractions were obtained based on thin layer chromatographic analysis. Five major compounds (Ee1 to Ee5) were isolated and purified from the active methanol extract of this species by silica gel column and TLC (Tables 1 and 2).

The ultraviolet spectrum of Ee-1, Ee-2, Ee-3, Ee-4, Ee-5 compounds were determined in spectral grade methanol and shown absorption maximum as: $\lambda \max =213 \mathrm{~nm}$ and $\lambda \max =269 \mathrm{~nm}, \lambda \max =217 \mathrm{~nm}$ and $\lambda \max =268 \mathrm{~nm}, \lambda \max =215 \mathrm{~nm}$ and $\lambda \max =275 \mathrm{~nm}, \lambda \max =207 \mathrm{~nm}$ and $\lambda \max =237 \mathrm{~nm}$ and $275 \mathrm{~nm}$ respectively (Figures 1, 3, 5, 7 and 9).

The infrared spectrum of Ee-1, Ee-2, Ee-3, Ee-4, Ee-5 compound exhibited absorption maximum at 3437 (medium), 2078 (broad) and 1637 (sharp) $\mathrm{cm}^{-1}, 3370$ (medium) and 1459 (sharp) $\mathrm{cm}^{-1}, 3419$ (medium) 2924 sharp) and 1459 (sharp) $\mathrm{cm}^{-1}$ and 3387 (medium) 2114 (broad) and 1644 (sharp) $\mathrm{cm}^{-1}$ respectively (Figures $2,4,6,8$ and 10). The results of methanol extract and its five isolated compound showed

\begin{tabular}{|c|c|c|c|c|c|c|}
\hline \multirow{2}{*}{$\begin{array}{l}\text { Pooled } \\
\text { Fraction }\end{array}$} & \multirow{2}{*}{ Eluting Solvent } & \multirow{2}{*}{ No of Compounds } & \multirow{2}{*}{ rf Values } & \multicolumn{3}{|c|}{ Detecting Agents } \\
\hline & & & & UV Light & lodine & Leibermann \\
\hline 1 & $\mathrm{CHCl}_{3}(100 \%)$ & 1 & 94 & Light blue & Yellow & Light grey \\
\hline 2 & $\mathrm{CHCl}_{3}(100 \%)$ & 1 & 91 & Light blue & Yellow & Light grey \\
\hline 3 & $\mathrm{CHCl}_{3}(100 \%)$ & 1 & 90 & Light blue & Yellow & No colour \\
\hline 4 & $\mathrm{CHCl}_{3}:$ Meoh (95:5) & 1 & 86 & Light blue & Yellow & No colour \\
\hline 5 & $\mathrm{CHCl}_{3}:$ Meoh (95:5) & 1 & 80 & Light blue & Dark yellow & No colour \\
\hline 6 & $\mathrm{CHCl}_{3}:$ Meoh $(95: 10)$ & 2 & 80,83 & Light blue, Blue & Dark yellow & Light grey, Grey \\
\hline 7 & $\mathrm{CHCl}_{3}: \mathrm{MeoH}(90: 20)$ & 1 & 45 & Off white & Dark yellow & No colour \\
\hline 8 & $\mathrm{CHCl}_{3}:$ Meho $(80: 20)$ & 2 & 53,88 & Sky blue, Blue & Yellow, Light & Yellow \\
\hline 9 & $\mathrm{CHCl}_{3}:$ Meoh (8020) & 1 & 67 & Bluish green & Yellow & Light grey \\
\hline 10 & $\mathrm{CHCl}_{3}:$ Meoh $(80: 20)$ & 1 & 68 & Bluish green & Yellow & No Color \\
\hline
\end{tabular}

Table 1: Comparative thin layer chromatographic analysis of pooled column fractions of methanol extract of $E$. echinatus. 
Citation: Younus M, Khan FZ, Sultana S, Asif HM (2016) Spectral Analysis and Antibacterial Activity of Methanol Extract of Roots of Echinops echinatus and its Fractions. J Microb Biochem Technol 8: 216-221. doi: 10.4172/1948-5948.1000288

\begin{tabular}{|c|c|c|c|c|c|}
\hline \multicolumn{2}{|c|}{ Solvent System } & \multirow[b]{2}{*}{ No. of Compounds } & \multicolumn{2}{|c|}{ Detection } & \multirow[b]{2}{*}{ Rf values } \\
\hline Solvents & Ratio & & UV Light & lodine & \\
\hline $\mathrm{MeOH}: \mathrm{CHCL}_{3}$ & $90: 10$ & 2 & Blue, Blue & Yellow, Yellow & 31,6 \\
\hline $\mathrm{MeOH}: \mathrm{CHCL}_{3}$ & $90: 20$ & 2 & Blue, Purple & Yellow, Brown & 16,34 \\
\hline $\mathrm{MeOH}: \mathrm{CHCL}_{3}$ & $80: 20$ & 2 & Light blue, Blue & Yellow, Yellow & 34,33 \\
\hline $\mathrm{MeOH}: \mathrm{CHCL}_{3}$ & $80: 30$ & 2 & Sky blue, Purple & Light Yellow, Yellow & 30,32 \\
\hline $\mathrm{MeOH}: \mathrm{CHCL}_{3}$ & $70: 20$ & 2 & Bluish green, Blue & Yellow, Dark Yellow & 18,28 \\
\hline $\mathrm{MeOH}: \mathrm{CHCL}_{3}$ & $70: 30$ & 2 & Blue, Pink & Yellow, Dark Yellow & 30,38 \\
\hline $\mathrm{MeOH}: \mathrm{CHCL}_{3}$ & $60: 40$ & 3 & Sky blue, Pink, Blue & Yellow, Brown, Light green & $34,46,40$ \\
\hline $\mathrm{MeOH}: \mathrm{CHCL}_{3}$ & $60: 50$ & 3 & Blue, Sky blue, Blue & Yellow, Dark yellow, Light yellow & $18,34,32$ \\
\hline $\mathrm{MeOH}: \mathrm{CHCL}_{3}$ & $40: 60$ & 2 & Off white, Sky blue & Yellow, Yellow & 14,48 \\
\hline $\mathrm{MeOH}: \mathrm{CHCL}_{3}$ & $40: 70$ & 2 & Blue, Bluish green & Yeloow, Dark yellow & 31,43 \\
\hline $\mathrm{MeOH}: \mathrm{CHCL}_{3}$ & $40: 80$ & 2 & Light green, Grey & Light yellow, Brown & 12,43 \\
\hline $\mathrm{MeOH}: \mathrm{CHCL}_{3}$ & $20: 80$ & 1 & Grey & Yellow & 15 \\
\hline $\mathrm{MeOH}: \mathrm{CHCL}_{3}$ & $20: 90$ & 2 & Sky blue, Blue & Light yellow, Dark yellow & 16,41 \\
\hline $\mathrm{MeOH}$ & $100 \%$ & 2 & Light green, Blue & Brown, Yellow & 15,38 \\
\hline
\end{tabular}

Table 2: Comparative thin layer chromatographic analysis of methanol extract of $E$. echinatus.

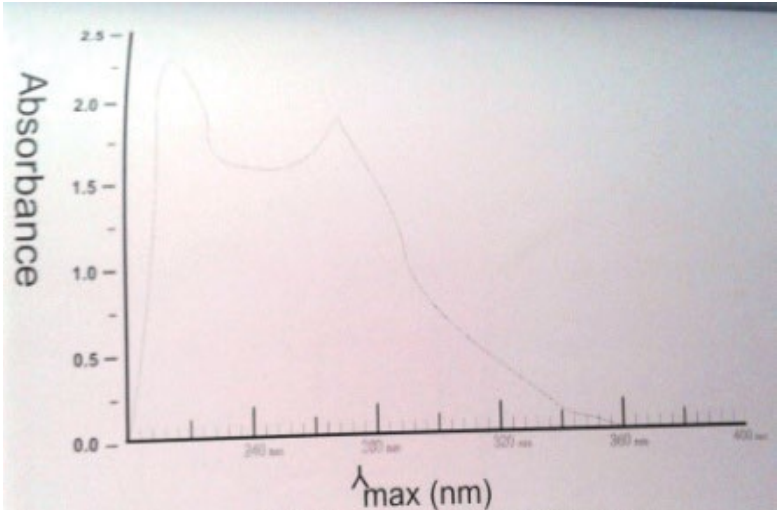

Figure 1: UV peak of compound Ee-1.

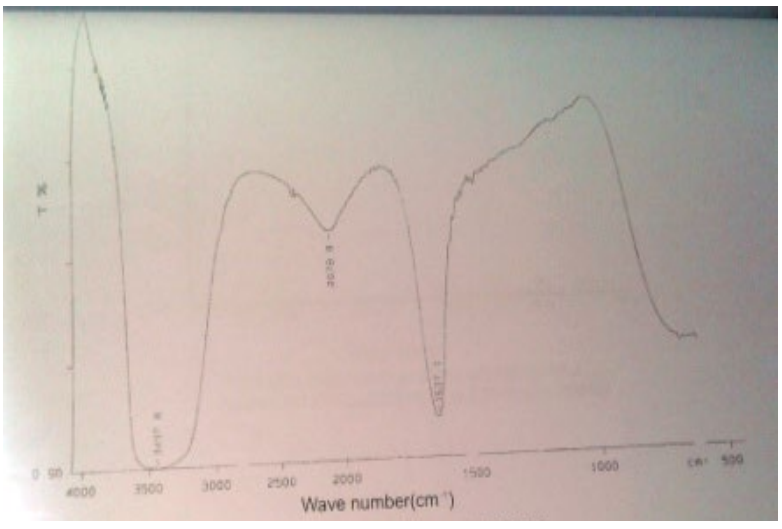

Figure 2: IR peak of compound Ee-1.

significant antibacterial activity against all types of bacteria. However maximum activity shown by Ee- 4 , Ee- 1 , Ee- 3 compound against Staphylococcus aureus $(17.0 \mathrm{~mm}),(15.3 \mathrm{~mm}),(12.3 \mathrm{~mm})$ respectively. While Ee-5 give maximum activity against E. coli $(13.5 \mathrm{~mm})$ (Table 3$)$.

Echinops echinatus plants, collected from Jauhar Town and

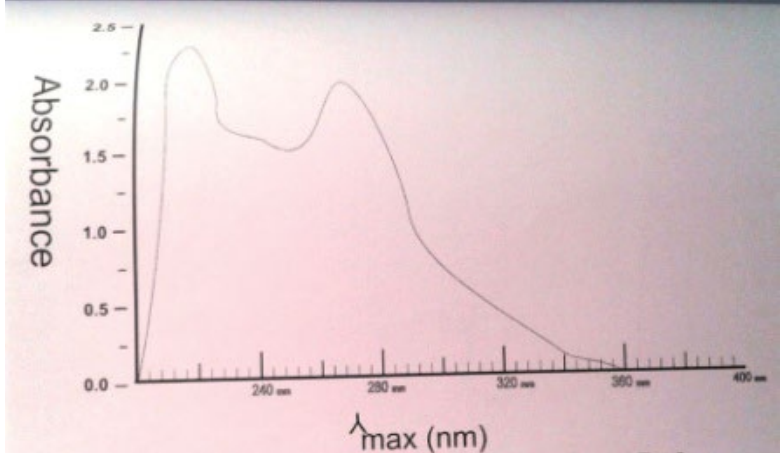

Figure 3: UV peak of compound Ee-2.

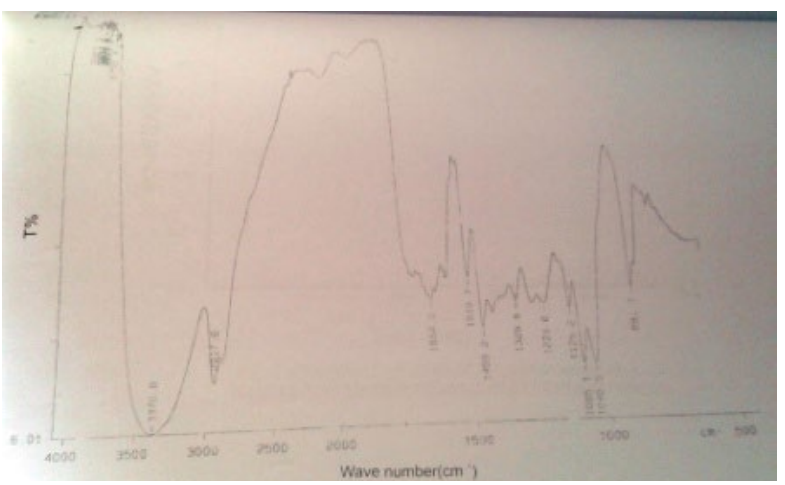

Figure 4: IR peak of compound Ee-2.

different waste places around Raiwind Road, Lahore, appeared to have variable appearance. During collection in different seasons from different localities, it was found that climatic conditions may affect the appearance of the plants. On the basis of such ecological variations, it was postulated that plants of this Asteraceae species might contain diverse types of secondary metabolities. The plants of this species are often found as weeds in the fields of other economical crops. This particular local species of Asteraceae has antimicrobial potentials and wide implementations [8]. Among antimicrobial properties, antibacterial 
Citation: Younus M, Khan FZ, Sultana S, Asif HM (2016) Spectral Analysis and Antibacterial Activity of Methanol Extract of Roots of Echinops echinatus and its Fractions. J Microb Biochem Technol 8: 216-221. doi: 10.4172/1948-5948.1000288

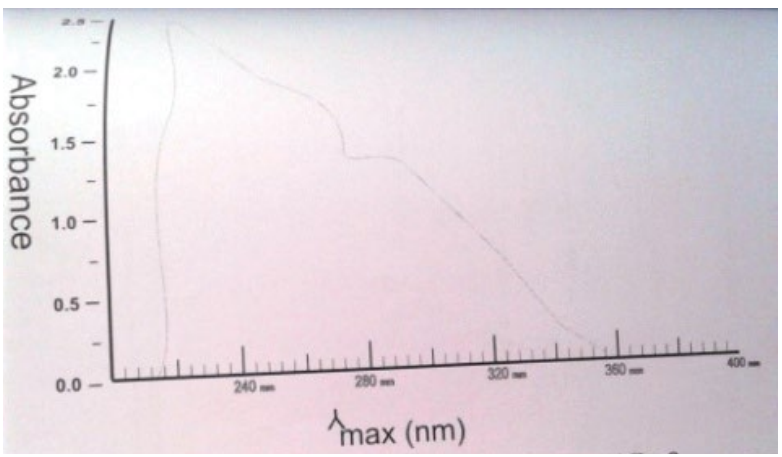

Figure 5: UV peak of compound Ee-3.

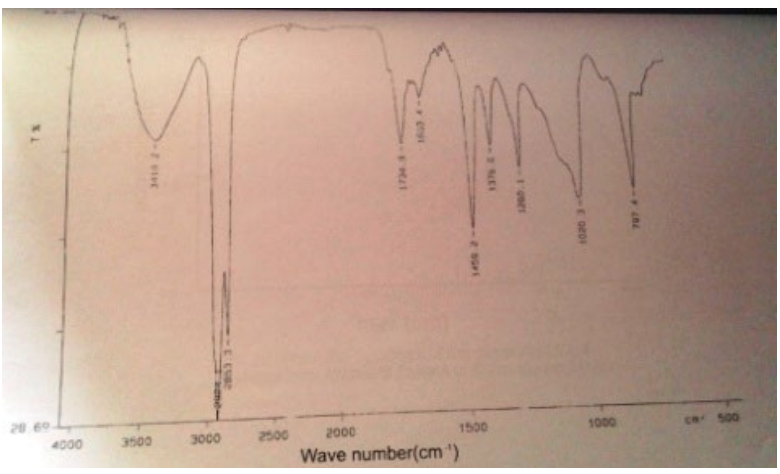

Figure 6: IR peak of compound Ee-3.

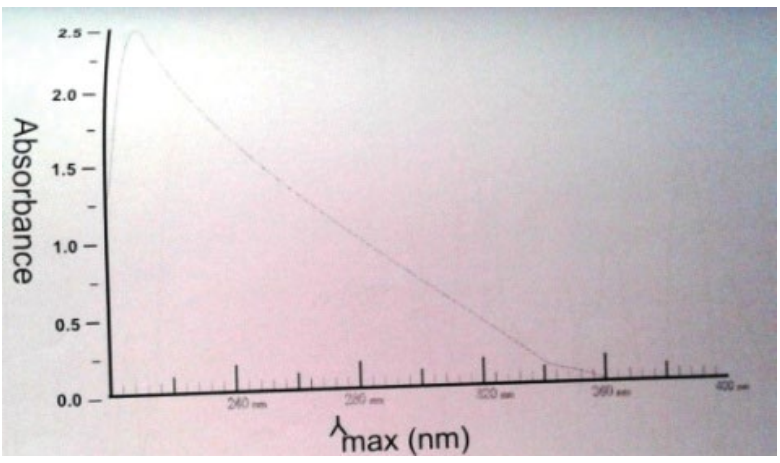

Figure 7: UV peak of compound Ee-4.

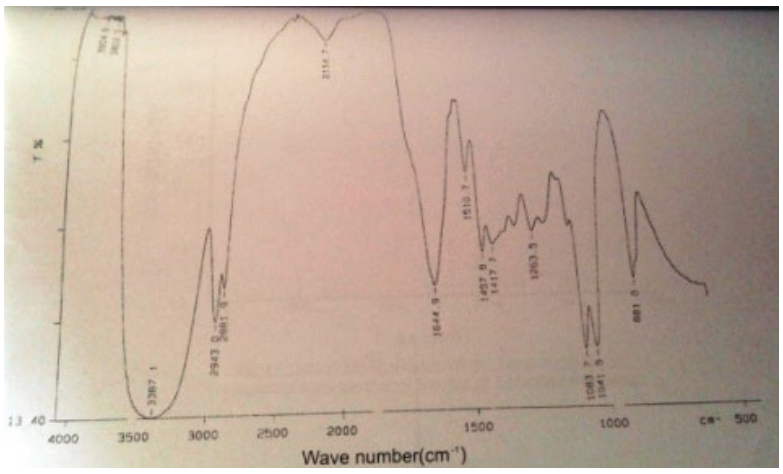

Figure 8: IR peak of compound Ee-4.

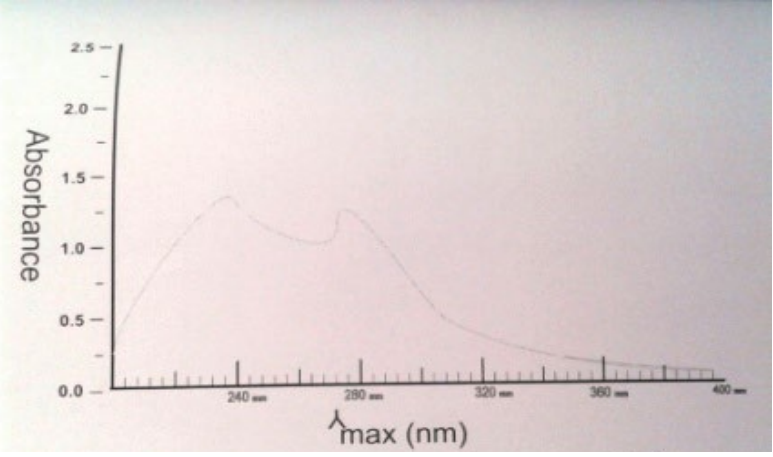

Figure 9: UV peak of compound Ee-5.

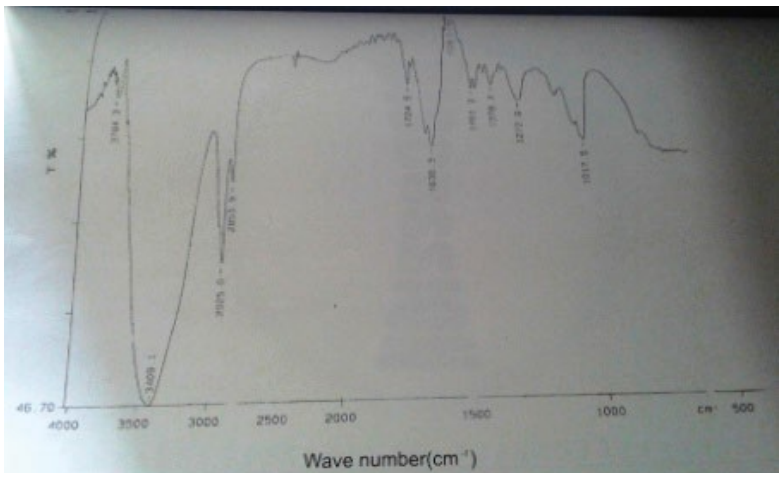

Figure 10: IR peak of compound Ee-5.

\begin{tabular}{|c|c|c|c|c|c|c|c|}
\hline \multirow{2}{*}{ Bacterial strains } & \multicolumn{9}{|c|}{ Zones of Inhibiton $\mathbf{~ m m})^{*}$} \\
\cline { 2 - 8 } & Ampici 1 mg/mI & Strep 1 mg/mI & Ee-1 & Ee-2 & Ee-3 & Ee-4 & Ee-5 \\
\hline Staphylococcus aureus & 30 & 25 & 15.3 & 14.5 & 11.8 & 17.00 & 10.7 \\
\hline Bacillus subtilis & 28 & 25 & 14.2 & 11.3 & 11.2 & 10.3 & 11.2 \\
\hline Streptococus pneumonia & 18 & 23 & 10.0 & 12.9 & 12.3 & 10.5 & 11.2 \\
\hline Escherichia coil & 19 & 30 & 12.5 & 13.2 & 11.00 & 12.0 & 13.5 \\
\hline Klebsiella pneumonia & 14 & 25 & 12.5 & 12.8 & 10.00 & 9.2 & 8.00 \\
\hline Pseudomonas aeruginosa & 14 & 24 & 6.00 & 10.00 & 12.00 & 5.9 & 7.95 \\
\hline
\end{tabular}

Table 3: Comparative antibacterial activity of the compounds Ee-1 to Ee-5, isolated from methanol extract of $E$. echinatus, ampicillin and streptomycin.

potential is another parameter, which was also investigated in this species, against three gram positive and three gram negative bacteria. The crude powdered material of the roots was subjected to antibacterial assay, which was followed by the isolation of antibacterial compounds.
The methanol extract subjected to column chromatographic analysis to isolate compound(s) using an increasing quantity of methanol in chloroform. The elution process was monitored by TLC. Ten pooled fractions were obtained based on thin layer chromatographic analysis. 
Five major compounds (Ee1 to Ee5) were isolated and purified from the active methanol extract of this species by silica gel column and TLC.

Compound Ee-1 was isolated from the first column fraction. It was a pale yellow and oily compound. TLC of this compound showed only single major spot, when a number of solvent systems were used. It gave yellow colour with iodine vapours when observed under ordinary light. Under UV light spot appeared with light blue quenching fluorescence. It also gave light grey spot on TLC plates when treated with Leibermann reagent. It probably indicated some alcohol/ phenol/steroid/carbonyl group $[9,10]$. The ultraviolet spectrum of this compound was determined in spectral grade methanol and shown absorption maximum as:

$\lambda \max =213 \mathrm{~nm}$ and $\lambda \max =269 \mathrm{~nm}$ (Figure 4). The strong absorption at $\lambda \max =213 \mathrm{~nm}$ was probably due to presence of open chain diene; while at $\lambda \max =269 \mathrm{~nm}$ was due to substituted ring, because benzene absorbs at $255 \mathrm{~nm}$ but the ring corners cause bathochromic shift, so it shows the presence of an aromatic ring with some conjugated diene chromophoric system present in its molecule [11].

The infrared spectrum of Ee-1 compound (Figure 5) exhibited absorption maximum at 3437 (medium), 2078 (broad) and 1637 (sharp) $\mathrm{cm}^{-1}$.The infrared spectrum showed a broad intermolecular hydrogen bonding around $3437 \mathrm{~cm}^{-1}$ due to $-\mathrm{OH}$ showing presence of some alcoholic/phenolioc hydroxyl group. The broadening of this bond emphasizes the stretching vibration of $-\mathrm{OH}$ with intermolecular $\mathrm{H}$-bonded at $\mathrm{OH}$. There was another possibility that this broad band of $\mathrm{OH}$ absorption in this region of IR might arise due to free water vapours that were incorporated in the compound during recording the spectrum. The band at $2078 \mathrm{~cm}^{-1}$ showed stretching vibration present in alkane. Often such bands are shown by methyl or methylene or aryl groups resulted from symmetrical or asymmetrical stretching $\mathrm{C}-\mathrm{H}$ modes. The presence and the number of $-\mathrm{CH}_{3}=\mathrm{CH}_{2}$ and $\equiv \mathrm{CH}$ groups in the molecule were further indicated by the peaks in the finger print region at 1500,1200 and $1000 \mathrm{~cm}^{-1}$. A strong peak at $1637 \mathrm{~cm}^{-1}$ indicated the presence of a coupled $\mathrm{C}=\mathrm{C}-\mathrm{C}=\mathrm{C}$ conjugated diene (alkene) with aromatic ring. [11-13]. The available spectral evidence showed that the compound Ee-1 was probably a conjugated diene containing methyl, aryl, ketonic, aldehydic, carboxylic acid along with some -OH group.

Compound Ee-2 was isolated from the second column fraction. It was a light yellow oily compound and chromatographically pure. TLC of this compound showed only single major spot, when a number of solvent systems were used. It gave yellow colour with iodine vapours and when observed under ordinary light. Under UV light spot appeared with light blue quenching fluorescence. It also gave light grey spot on TLC plates when treated with Leibermann reagent. The ultraviolet spectrum of this compound was determined in spectral grade methanol and shown absorption maximum as: $\lambda \max =217 \mathrm{~nm}$ and $\lambda \max =268 \mathrm{~nm}$ (Figure 6). The strong absorption at $\lambda \max =217 \mathrm{~nm}$ was probably due to $\pi$ to $\boldsymbol{B}^{*}$ transition because of butadiene (conjugated system); while at $\lambda \max =268 \mathrm{~nm}$ was due to substituted benzene ring, because benzene absorbs at $255 \mathrm{~nm}$ but the ring corners cause bathochromic shift, so it shows the presence of an aromatic ring with some conjugated diene chromophoric system present in its molecule $[11,12]$.

The infrared spectrum of this compound (Figure 7) exhibited absorption maximum at 3370 (medium) and 1459 (sharp) $\mathrm{cm}^{-1}$. The infrared spectrum of Ee-2 showed a number of strong and weak intensity bands. A band at at $3370 \mathrm{~cm}^{-1}$ is absorption frequency of triple bond showed the presence of alkyne, i.e., $\equiv \mathrm{C}-\mathrm{H}$ or $-\mathrm{C} \equiv \mathrm{C}-\mathrm{H}$. Presence of a medium band at $2937 \mathrm{~cm}^{-1}$ showed $\mathrm{C}-\mathrm{H}$ aliphatic asymmetric stretch.
This band resulted from symmetrical and asymmetrical stretching mode in which two - $\mathrm{CH}$ bands of methyl groups were extending, while third one was contracting.

The presence and the number of $-\mathrm{CH}_{3}=\mathrm{CH}_{2}$ and $\equiv \mathrm{CH}$ groups in the molecule were further indicated by the peaks in the finger print region between $2500 \mathrm{~cm}^{-1}$ and $1600 \mathrm{~cm}^{-1}$. A band at $1654 \mathrm{~cm}^{-1}$ indicated the presence of a coupled $\mathrm{C}=\mathrm{C}-\mathrm{C}=\mathrm{C}$ conjugated diene (alkene) with aromatic ring $[11,12]$. Peaks in the finger print region of $1510 \mathrm{~cm}^{-1}, 1459$ $\mathrm{cm}^{-1}, 1221 \mathrm{~cm}^{-1}$ and $1125 \mathrm{~cm}^{-1}$ showed the presence of carbonyl group. Peaks at $1085 \mathrm{~cm}^{-1}$ and $1040 \mathrm{~cm}^{-1}$ showed C-N stretch, while at $881 \mathrm{~cm}^{-1}$ showed $\mathrm{N}-\mathrm{H}$ wagging movement. The available data showed that the compound Ee-2 was probably a conjugated alkyne with aromatic ring.

Compound Ee-3 was isolated and purified from the fourth column fraction. It was a light yellow compound and chromatographically pure. TLC of this compound showed only single major spot, when a number of solvent systems were used. It gave yellow colour with iodine vapours and ordinary light. Under UV light spot appeared with light blue quenching fluorescence and yellow colour with iodine. The ultraviolet spectrum of this compound was determined in spectral grade methanol and shown absorption maximum as: $\lambda \max =215 \mathrm{~nm}$ and $\lambda \max =275$ $\mathrm{nm}$ (Figure 8). The compound 3 had a strong absorption at $\lambda \max =215$ $\mathrm{nm}$ and $\lambda \max =275 \mathrm{~nm}$. The strong absorption at $\lambda \max =215 \mathrm{~nm}$ was probably due to $ה$ to $\pi^{*}$ transition, the compound may be $\alpha, \beta$ conjugated six-ring or acyclic ketone; while at $\lambda \max =275 \mathrm{~nm}$ was due to disubstituted, benzene rings and is the positive identification of a ketone or aldehyde carbonyl group, it gives rise to yellow colour of the compound $[11,12]$.

The infrared spectrum of this compound (Figure 9) exhibited absorption maximum at 3419 (medium) 2924 sharp) and 1459 (sharp) $\mathrm{cm}^{-1}$. The infrared spectrum of Ee-3 showed a broad intermolecular hydrogen bonding around 3419 broadening of this bond emphasizes the stretching vibration of $-\mathrm{OH}$ with intermolecular $\mathrm{H}$-bonded at $\mathrm{OH}$. There was another possibility that this broad band of $\mathrm{OH}$ absorption in this region of IR might arise due to free water vapours that were incorporated in the compound during recording the spectrum. Two bands at 2924 and $2853 \mathrm{~cm}^{-1}$ showed the presence of single bonds due to $\mathrm{C}-\mathrm{H}$ stretching; or these may be saturated $\mathrm{C}-\mathrm{H}\left(-\mathrm{CH}_{3}\right)$ and $\mathrm{C}-\mathrm{C}$ in the form of 2 or 3 bonds, usually there are two characteristic bands due to $\mathrm{C}-\mathrm{H}$ stretch in aldehyde. $1734 \mathrm{~cm}^{-1}$ showed $\mathrm{C}=\mathrm{O}$ stretch due to some carbonyl group, may some saturated aldehyde or ketone and indicative of sesquiterpines. Peak at $1653 \mathrm{~cm}^{-1}$ indicated the presence of a coupled $\mathrm{C}=\mathrm{C}-\mathrm{C}=\mathrm{C}$ conjugated diene (alkene) with aromatic ring [11-13]. Peaks at 1260,1020 and $797 \mathrm{~cm}^{-1}$ in the finger print region were indicative of -C-O-C- linkage. The available spectral data showed that the compound Ee-3 was probably a carbonyl compound with substituted benzene ring along with some $-\mathrm{OH}$ group due to some alcohol or phenol.

The compound Ee- 4 was isolated and purified from the sixth column fraction. It was a dark yellow compound and chromatographically pure. This compound on TLC exhibited two spots, when a number of solvent systems were used. It gave dark yellow and yellow colour with iodine vapours and blue fluorescence under UV light. These gave light grey and grey colours with Leibermann reagent. The ultravioted spectrum of this compound was determined in spectral grade methanol and shown absorption maximum as: $\lambda \max =207 \mathrm{~nm}$ (Figure 10). The compound Ee- 4 had a strong absorption at $\lambda \max =207 \mathrm{~nm}$. The strong absorption at $\lambda \max =207 \mathrm{~nm}$ was probably due to $ה$ to $ה^{*}$ transition, which suggested that the compound may be $\alpha, \beta$ unsatured ketone or aldehyde $[11,12]$. The infrared spectrum of this compound exhibited absorption maximum at 3387 (medium) 2114 (broad) and 1644 (sharp) $\mathrm{cm}^{-1}$. 
Citation: Younus M, Khan FZ, Sultana S, Asif HM (2016) Spectral Analysis and Antibacterial Activity of Methanol Extract of Roots of Echinops echinatus and its Fractions. J Microb Biochem Technol 8: 216-221. doi: 10.4172/1948-5948.1000288

The infrared spectrum of Ee-4 showed a number of strong and weak intensity bands. A band at $3387 \mathrm{~cm}^{-1}$ is absorption frequency of triple bond showed the presence of alkyne, i.e., $\equiv \mathrm{C}-\mathrm{H}$ or $-\mathrm{C} \equiv \mathrm{C}-\mathrm{H}$. Presence of two bands at 2943 and $2881 \mathrm{~cm}^{-1}$ showed the presence of single bonds due to $\mathrm{C}-\mathrm{H}$ stretching; or these may be saturated $\mathrm{C}-\mathrm{H}\left(-\mathrm{CH}_{3}\right)$ and $\mathrm{C}-\mathrm{C}$ in the form of two or three bands, usually there are two characteristic bands due to $\mathrm{C}-\mathrm{H}$ stretch in aldehyde. The band at $2114 \mathrm{~cm}^{-1}$ showed stretching vibration present in alkane. Often such bands are shown by methyl or methylene or aryl groups resulted from symmetrical or asymmetrical stretching C-H modes. Two medium bands in 1644 and $1510 \mathrm{~cm}^{-1}$ region were shown by six membered aromatic system ring such as benzene and polycyclic systems. The presence and the number of $-\mathrm{CH}_{3}=\mathrm{CH}_{2}$ and $\equiv \mathrm{CH}$ groups in the molecule were further indicated by the peaks in the finger print region at 1263,1083 and $1041 \mathrm{~cm}^{-1}$. Two bands at 1083 and $1041 \mathrm{~cm}^{-1}$ were shown due to $\mathrm{C}-\mathrm{O}$ stretching in $\mathrm{C}-\mathrm{O}-\mathrm{C}$ compounds. A band at $881 \mathrm{~cm}^{-1}$ was produced by the out plane of $\mathrm{C}-\mathrm{H}$ bending vibrations. The available spectral data showed that the compound Ee-4 was probably a conjugated aromatic alkyne or alkene.

Compound Ee- 5 was isolated and purified from the seventh column fraction. It was a dark yellow oily compound and chromatographically pure. TLC of this compound showed only single major spot, when a number of solvent systems were used. It gave dark yellow colour with iodine vapours and ordinary light. Under UV light spot appeared as off white fluorescence. The ultraviolet spectrum of this compound was determined in spectral grade methanol and shown absorption maximum as; $A m a x=237 \mathrm{~nm}$ and $275 \mathrm{~nm}$. The compound had a strong absorption at $\lambda \max =237 \mathrm{~nm}$ and $\lambda \max =275 \mathrm{~nm}$. The strong absorption at $\lambda \max =237 \mathrm{~nm}$ was probably due to $ה$ to $\pi^{*}$ transition, the compound may be an acyclic diene with 2-alkyl group, one each on $\alpha$ and $\beta$ position; while at $\lambda \max =275 \mathrm{~nm}$ was due to disubstituted, benzene rings and is the positive identification of a ketone or aldehyde carbonyl group, it gives rise to yellow colour of the compound [11-13].

The infrared spectrum of the compound Ee- 5 exhibited absorption maximum at 3409 (medium) 2925 (sharp) and 1636 (sharp) $\mathrm{cm}^{-1}$. The infrared spectrum of Ee- 5 showed a broad intermolecular hydrogen bonding around $3409 \mathrm{~cm}^{-1}$ due to $-\mathrm{OH}$ showing presence of some alcoholic/phenolioc hydroxyl group. The broadening of this bond emphasizes the stretching vibration of $-\mathrm{OH}$ with intermolecular $\mathrm{H}$-bonded at $\mathrm{OH}$. There was another possibility that this broad band of $\mathrm{OH}$ absorption in this region of IR might arise due to free water vapours that were incorporated in the compound during recording the spectrum. Two bands at 2925 and $2853 \mathrm{~cm}^{-1}$ showed the presence of single bond due to $\mathrm{C}-\mathrm{H}$ stretching vibration; these may be saturated $\mathrm{C}-\mathrm{H}\left(-\mathrm{CH}_{3}\right)$ and $\mathrm{C}-\mathrm{C}$ in the form of two or three bands, usually there are two characteristic bands due to $\mathrm{C}-\mathrm{H}$ stretch in aldehyde. The presence and the number of $-\mathrm{CH}_{3}=\mathrm{CH}_{2}$ and $\equiv \mathrm{CH}$ groups in the molecule were further indicated by the peaks in the finger print region. A strong peak at $1636 \mathrm{~cm}^{-1}$ indicated the presence of a coupled $\mathrm{C}=\mathrm{C}-\mathrm{C}=\mathrm{C}$ conjugated diene (alkene) with aromatic ring; it may be $\alpha, \beta$ unsaturated carbonyl compounds, usually much weaker than $\mathrm{C}=\mathrm{O}$ band [11-13]. A band at $1378 \mathrm{~cm}^{-1}$ showed $\mathrm{C}-\mathrm{H}$ bend for $-\mathrm{CH}_{3}$ symmetrical deformation; while another band at $1272 \mathrm{~cm}^{-1}$ was for $-\mathrm{CH}_{3}$ group stretch. Appearance of a band at $1017 \mathrm{~cm}^{-1}$ was due to $\mathrm{C}-\mathrm{O}$ stretching in C-O-C compounds showing the presence of carbonyl group. The available spectral evidence showed that the compound Ee-5 was probably a conjugated diene containing methyl, aryl, ketonic, aldehydic, carboxylic acid along with some -OH group due to some alcohol or phenol.

All the five compounds Ee 1- Ee 5 were active, displayed well marked inhibitory effects against the six types of bacteria, as potent as standard antibiotics. Since these compounds contain $-\mathrm{OH},-\mathrm{COOH}$, or ketonic group and a double bond with conjugated diene system in their molecules, probably penetrated through the bacterial cell and retard their growth or completely killed them. The results found in this investigation were similar to the previous findings by other workers who explored the antimicrobial potentials of natural products, against a large number of microorganisms, particularly from the various members of the Asteraceae family [8]. It could be concluded that a contingent chemical characterization of these phytochemical compounds is obligatory, so that a structure-activity relationship of such important molecules in terms of antimicrobial activities could be established.

\section{Acknowledgement}

The authors are grateful to the Principal, College of Pharmacy, University of Punjab, Lahore for their counsel and guidance and support during the entire research period.

\section{References}

1. Kashyap SR, Joshi AC (1936) Composite Lahore University Flora. Lahore, The University of the Punjab.

2. Khan MA, Niazi HH (2000) Ethnobotany and taxonomic studies of $E$. echinatus Roxb. from Potohar region of Pakistan. Hamdard Medicus 10: 3.

3. Chaudhri PK (1987) Echinozolinone and alkaloids form Echinops echinatus Phytochemistry 26: 587-589.

4. Chaudhri PK (1988) Constituents of the flowers of Echinops echinatus Fitoterapia 59: 150-151.

5. Shukla YN (2003) Chemical, botanical and pharmacological studies on the genus Echinops: A review. Jr Med and Arom Plan Sc 25: 720-732.

6. Stahl E (1969) Thin layer chromatography; spray reagents. ( $2^{\text {nd }}$ edn), The Springer Veralg, New York, USA.

7. Milton JS, Tsokos JD (1983) Statistical methods in Biology and Health Science. McGraw-Hill, Tokyo, Japan

8. Sharma S, Metha BK (1989) Antimicrobial activity of Echinops echinatus roo extract. ABIM 6: 82-83.

9. Brain KR, Turner TD (1975) The practical evaluation of Phytopharmaceuticals Wright-Scientechnica, Bristol, UK.

10. Egon S (1969) Thin layer chromatography: A Laboratory Handbook. Toppan Company, Tokyo, Japan.

11. Williams DH, Fleming I (1988) Spectroscopic methods in organic chemistry. (4th edn), Tata Mc-Graw Hill Publishing Co.Ltd., New Delhi, India.

12. SharmaYR, Acharya RC (1987) Analytical methods in chemistry. ( $1^{\text {st }}$ edn), Kalyani Publishers, New Delhi, India.

13. Parimoo $P$ (1999) Pharmaceuticals analysis. (2 ${ }^{\text {nd }}$ edn), CBS Publishers and Distributors, New Deilhi, India. 